\title{
THE EPIDEMIOLOGICAL CHALLENGES OF BREAST CANCER AMONG PREMENOPAUSAL WOMEN IN LIMITED RESOURCE SETTINGS
}

\author{
Gabriela Torres-Mejía ${ }^{1}$, Edgar Navarro-Lechuga ${ }^{2}$, Rafael de Jesús Tuesca-Molina ${ }^{2}$ \\ AND ANGÉLICA ÁNGELES-Llerenas ${ }^{1 *}$ \\ ${ }^{1}$ Centro de Investigación en Salud Poblacional, Instituto Nacional de Salud Pública, SSA, Cuernavaca, Mor., Mexico; \\ 2Departamento de Salud Pública, Universidad del Norte, Barranquilla, Colombia
}

\begin{abstract}
Breast cancer is the most common malignant tumor among women of reproductive age and is also the most costly according to European reports. In this context, the aim of the present review is to identify factors that make breast cancer in premenopausal women an epidemiological challenge in developing countries. Epidemiological aspects of breast cancer, including risk factors, early detection methods, and treatment, are addressed. Breast cancer in premenopausal women should be included in the political and strategic agendas in developing countries to direct the necessary resources for prevention, detection, and control. (REV INVES CLIN. 2017;69:59-65)
\end{abstract}

Key words: Breast cancer. Premenopausal women. Limited resource setting.

\section{INTRODUCTION}

Breast cancer is the most common malignant tumor among women of reproductive age and is the most costly according to reports from the European community ${ }^{1}$. In developing countries, the available resources assigned to health care are primarily aimed at infectious disease control ${ }^{2}$; therefore, more resources are needed to detect, diagnose, and treat chronic diseases such as breast cancer and especially to control this disease in premenopausal women. In this context, the aim of this review is to identify aspects that make breast cancer in premenopausal women an epidemiological challenge in developing countries.

\section{STATISTICS}

There is international variation in the incidence and mortality rates of breast cancer ${ }^{3}$. Although this disease has been considered a pathology of developed countries, more than half of new cases ( $52 \%$ ) and deaths $(62 \%)$ occur in developing countries ${ }^{4}$. The

\section{Corresponding author:}

*Angélica Ángeles-Llerenas

Instituto Nacional de Salud Pública

Av. Universidad 655

Colonia Santa María Ahuacatitlán

C.P. 62100, Cuernavaca, Mor., México

E-mail aangelica@insp.mx 
highest incidence rates are seen in developed countries $^{3}$, and the breast cancer incidence rate adjusted for age in premenopausal women in such countries is higher (29.4 cases per 100,000 woman-years) than that in developing countries ( 12.8 cases per 100,000 woman-years). Of all cancer incidences, $47.3 \%$ correspond to premenopausal women in developing countries compared to $18.5 \%$ in developed countries ${ }^{5}$. Furthermore, it has been reported that in developing countries, the average age at diagnosis is 10 years younger ${ }^{6-9}$. This fact is mainly a result of the younger demographic composition of developing countries $^{4,5,10}$. It has also been suggested that certain risk factors may explain this age-related diagnosis disparity.

\section{RISK FACTORS}

The early presentation of breast cancer in developing countries has been attributed to the younger demographic composition of these countries ${ }^{5,11}$. For example, a retrospective study was performed at Ahmadu Bello University Teaching Hospital in Nigeria, a country in which approximately $49 \%$ of the population is younger than 15 years of age ${ }^{12}$. In this study, the average age of participants with breast cancer was 44.5 years, the majority ( $57.4 \%$ ) was between 30 and 49 years of age, and $62 \%$ of the women were premenopausal ${ }^{13}$. Ghiasvand, et al. ${ }^{14}$ carried out a hospital-based case-control study that included 521 women with histologically confirmed breast cancer and 521 controls matched by age and place of residence. The authors determined that a trend of decreasing parity and reduced duration of breastfeeding, together with the use of oral contraceptives, may partially explain the rapid increase in breast cancer incidence in premenopausal women ${ }^{14}$. In accordance with other authors, Ghiasvand, et al. ${ }^{14}$ found that breast cancer incidence in premenopausal women has remained stable over several decades in both developing and developed countries ${ }^{15,16}$. Therefore, it has been suggested that the primary risk factors in this group of women are genetic factors and certain environmental factors that have remained constant ${ }^{5}$.

As knowledge on the genome expands, the challenges of this disease will be greater for developing countries $^{17}$. It has been observed in the USA that fewer tests to determine BRCA1 and BRCA2 mutations are performed in Black women compared to Caucasian women, due in part to less discussion on the topic by healthcare providers ${ }^{17}$. Given that the prevalence of BRCA mutations is higher in pre- than in postmenopausal women, the impact of disparities will be more frequently observed in the first group of women. A study performed in Mexico on patients with breast cancer showed a prevalence of BRCA1 and BRCA2 gene mutations of $11.8 \%$ in women from 30 to 39 years of age, $4.8 \%$ in women from 40 to 49 years, $3.4 \%$ in women from 50 to 59 years, and $1.6 \%$ in women aged 60 and older ${ }^{18}$.

In contrast, the increase in breast cancer incidence among postmenopausal women in developing countries is probably due to increases in risk factors associated with economic development and urbanization, such as obesity, adoption of Western dietary patterns $^{19}$, and physical inactivity ${ }^{20,21}$, combined with a later average age of first pregnancy and the resulting lower number of children, earlier menarche, and a shorter duration of breastfeeding ${ }^{21-25}$. Additionally, various studies have shown that the risk of breast cancer increases among postmenopausal women who migrate from developing to developed countries, while this has not been observed among premenopausal women ${ }^{5,26,27}$.

\section{SCREENING}

Screening with mammography is the only procedure that has been shown to reduce breast cancer mortality ${ }^{28}$, and early detection should therefore be the primary goal worldwide as no country has shown that metastatic cancer can be treated effectively ${ }^{29}$. In the majority of developing countries, it is not possible to implement organized screening programs using mammography and access to treatment is limited ${ }^{30}$. Consequently, many breast cancer patients only seek medical attention after the disease has reached an advanced clinical stage ${ }^{3}$. Meta-analyses of clinical trials of screening using mammography have shown $20 \%$ reductions in breast cancer mortality, with a greater benefit in postmenopausal women ${ }^{28}$ due in part to the mammographic density in premenopausal women ${ }^{31}$. Controversy exists, however, over whether the breast cancer mortality reduction afforded by mammography screening is due to the timely detection of small tumors using mammography or to 
advances in systemic treatment ${ }^{35}$. The use of mammography screenings is suspected by some of leading to over-diagnosis, which corresponds to the identification of non-malignant cancers that have no effect on survival but are still treated ${ }^{32}$. The foregoing, combined with the fact that most screening programs in developing countries are opportunistic ones that do not reduce breast cancer mortality and the fact that other screening strategies such as self-examination $^{33,34}$ and clinical examination ${ }^{35}$ also do not reduce breast cancer mortality, make screening in developing countries a challenge. The challenge is particularly difficult in premenopausal women, given the large number of women to screen in this population subset. Research in developing countries with the objective of contributing to knowledge in this area is essential. For example, in India there are results showing that improved awareness and access to treatment may contribute to lowering the clinical disease stage at first contact ${ }^{36}$.

\section{DIAGNOSIS AND DELAY CONCERNS}

Reducing care delivery times so that women may receive timely care is a challenge in developing countries. Delays in care in these countries lead to breast cancer diagnoses typically occurring when the disease is in an advanced stage, mostly in clinical stages III and IV ${ }^{37-39}$. In premenopausal women, this delay affects survival and, as a consequence, increases the potential years of life lost ${ }^{40}$. Some studies have shown that premenopausal women more frequently present with tumors of greater size, have a higher number of positive lymph nodes ${ }^{41,42}$, exhibit more aggressive tumors, and have worse prognoses when compared with postmenopausal women $39,43,44$. According to the suggestions of the World Health Organization (WHO) and the Breast Health Global Initiative (BHGI), developing countries should prioritize efforts to detect patients in earlier clinical stages by increasing awareness in women and access to treatment ${ }^{45}$. Detection of breast cancer in later clinical stages has been associated with delays in care $\mathrm{e}^{46,47}$ and with lower incomes ${ }^{48}$.

In developing countries, the timely diagnosis of breast cancer is a challenge and is not only due to the healthcare providers ${ }^{49}$. However, when a patient arrives to a tertiary care hospital with a breast cancer diagnosis, the diagnostic biopsy is typically repeated due to mistrust of procedures carried out in suburban communities. The NOM-041-SSA2-2011 for prevention, diagnosis, treatment, control, and epidemiological monitoring of breast cancer in Mexico, states that the time between biopsy and initiating treatment should be 25 days ${ }^{50}$. Prior studies have evaluated delays in diagnosis and initiation of treatment of women with breast cancer ${ }^{46,51,52}$; however, few studies have focused on analyzing whether these delays were greater among premenopausal women compared to postmenopausal women, and whether the reasons for delay differed between the two groups. Results of one study in 11 hospitals from six states in Mexico showed that the median time between biopsy and treatment initiation was 37 days, with an interquartile range of 18-63 natural days ${ }^{52}$. Similarly, a study carried out in three hospitals in Mexico City showed a median of 30 days for the same indicator ${ }^{53}$. In Brazil in 2013, Law No. 12.732/2012 established a period of 60 days between pathology diagnosis and initiation of treatment within the Unified Healthcare System (Sistema Único de Saúde - SUS) ${ }^{54}$. A study including 473 women was performed between 2009 and 2011 in the Oncology Centre of the Cariri, Brazil, in which 33\% of the population was premenopausal women, and a median of 71.5 days between diagnosis and treatment initiation was observed ${ }^{54}$. As evidenced by these delays, diagnostic processes have implications for the reproductive lives of patients ${ }^{55-58}$, for their family and work lives ${ }^{59}$, on their quality of life, and on survival ${ }^{52}$

\section{TUMOR BIOLOGY HETEROGENEITY CONCERNS}

Studies of genetic expression profiles have classified breast cancers into five subtypes: luminal $A$, luminal B, HER-2 overexpressing, basal-like, and breast-normal-like. Although the molecular differences between these subtypes have been described in the literature, there is extensive heterogeneity in the distribution of molecular subtypes ${ }^{44,60,61}$ and their causes around the world ${ }^{62}$. Further research is necessary to determine if these differences are due to tumor biology or rather to poor pre-analytic management of the samples, including differences in fixation times and improper interpretation ${ }^{63,64}$. There is a consensus in the literature that the prevalence of triple-negative tumors is 
greater in premenopausal women than in their postmenopausal counterparts ${ }^{65}$. Additionally, women younger than 50 years with triple-negative tumors are more likely to carry BRCA1 gene mutations, which justifies screening for such mutations in this particular group ${ }^{66,67}$.

\section{AWARENESS}

The need for novel strategies to increase awareness of the risk of breast cancer among premenopausal women is a challenge in developing countries. The frequent presentation of mammary tumors at advanced stages among premenopausal women may in part be because women of this age have less awareness of breast cancer risk and, as a result, of screening practices. Delays in diagnosis among premenopausal women have been explained by the lower incidence of malignant breast tumors and the high frequency of benign tumors in this age group, which may delay the initiation of treatment ${ }^{68}$ and affect survival ${ }^{52}$. It is necessary to increase awareness of breast cancer and the benefits of early detection, particularly in developing countries, to implement successful control programs and improve access to treatment ${ }^{3}$.

\section{Available resources}

Globally, healthcare resources scarcity is worsening, particularly in developing countries ${ }^{69}$. As described by the Global Health Initiative, to treat similar conditions developing countries have fewer resources in comparison with developed countries and consequently experience lower probabilities of survival ${ }^{70}$. One study showed that breast cancer survival at five years varied from $53 \%$ in South Africa to $89 \%$ in the USA ${ }^{71}$. In this study, among the 67 countries that reported fiveyear survival rates, this metric increased continuously in the majority of developed countries, as well as in certain countries in Central and South America (e.g., Brazil from 78 to $87 \%$, Colombia from 66 to $76 \%$, and Ecuador from 69 to $83 \%)^{71}$. In contrast, DeSantis, et al. ${ }^{3}$ showed that incidence rates and mortality from breast cancer increased in Colombia, Ecuador, and Japan, while mortality rates increased in Brazil, Egypt, Guatemala, Kuwait, Mauritius, Mexico, and the Republic of Moldova, reflecting limited access to early diagnosis and treatment ${ }^{3,30}$. Regarding healthcare management, developing countries tend to prioritize their decisions due to the very limited budgets they have for healthcare, which barely exceeded an average of US\$30 per capita in $2011^{72}$. In contrast with breast cancer survival rates in developing countries, rates in developed countries have improved in the last 20 years, and more women are being successfully treated $^{73}$.

In Latin America, innovative medications such as those used in cancer treatment have a higher cost than they do in developed countries, which limits access to treatment and imposes an economic burden on these countries ${ }^{74}$. For the first time in 2007, Mexico included breast cancer in the Catastrophic Health Expenditures Fund, which has reduced catastrophic spending and the impoverishment of families with patients suffering from this disease ${ }^{75,76}$. In developing countries, resources available for healthcare are assigned to infectious disease control ${ }^{2}$, and molecular diagnostic tests for selection of the appropriate breast cancer treatment, for example, are often not integrated into daily practice ${ }^{77}$. Additionally, the increasing costs of cancer care have been described to be due to unnecessary uses of certain procedures $^{78,79}$.

\section{TREATMENT}

The scarcity of high-cost medications such as trastuzumab and lapatinib for the management of very common molecular breast cancer subtypes in premenopausal women represents a challenge in developing countries, as do the prophylactic surgical procedures that are recommended for breast cancer patients with certain germline mutations ${ }^{80}$. One study reviewed the national essential medicine lists from 75 developing countries in which all listed components were included for treatment by clinical stage according to international consensus guidelines. The results showed that treatments for later-stage cases were more frequently selected as essential medicines than those used to treat early stage tumors ${ }^{80}$. Trastuzumab was approved for the first time over 15 years ago, and its patent will expire soon, which will provide an opportunity for greater access to this medicine in these countries. In the case of therapies directed at HER2-expressing tumors, trastuzumab was selected in less than $10 \%$ of the national essential medicine 
lists ${ }^{80}$. Regarding surgical treatments for patients with BRCA1/2 mutations, in the USA, prophylactic mastectomies and salpingo-oophorectomies were significantly less common among Black patients than among Latinas and Caucasians ${ }^{17}$. Still, more research is needed on these procedures ${ }^{81}$ in the interest of offering adequate genetic counseling for these patients. Women with hereditary history of breast cancer have three prophylactic options: screening, chemoprevention, and prophylactic surgery. However, to date there have been no clinical trials to test the efficacy of these approaches in patients with genetic mutations. As a result, women who are carriers should be informed about the three treatment options and should understand that the results to be expected for each are still in question ${ }^{55}$.

\section{A PUBLIC HEALTH VIEW}

Detection and care programs in countries with moderate and low incomes and with infrastructure and technology difficulties experience organizational, financial, economic, and cultural barriers that limit the applicability and effectiveness of health programs directed at women. Although representatives of various countries at the 2002 Seattle Conference recommended early detection, diagnosis, and treatment, as well as the adoption of guidelines that emphasize the actions in each disease stage and phase, these recommendations have not been universally adopted within healthcare systems. For some systems, this is due to the shortage of resources, low availability of trained professionals, and cultural, ethnic, and environmental differences (urban, rural, and social stratification), which limit opportunities for access and detection ${ }^{82-85}$.

It is important to recognize that developing countries experience the aforementioned barriers, sometimes in addition to shortcomings related to information systems and histopathology registries, which are intended to provide guidance in planning, research, and appropriate care of affected women. These countries likewise confront problems with social crises, political insecurity, war, and combinations of these factors that derail and obstruct healthcare, including efforts at early breast cancer detection. In these countries, it is necessary to include a strategic agenda for the control and care of this disease to improve breast cancer survival ${ }^{82-85}$. In the case of Latin America, many countries in the region have standards of care and programs for breast cancer detection and medical attention. However, despite these efforts, in each country, the barriers mentioned present disparities, segmentation, and fragmentation in the health system and healthcare services that generate a multitude of conditions that hinder and undermine the existing care standards ${ }^{38}$.

\section{CONCLUSIONS}

The detection of and mortality due to breast cancer vary among developed countries with stable health systems, while developing countries that have shortcomings in their health systems experience differences in the magnitude of costs, survival, and mortality due to this disease. While both national and international guidelines and protocols exist for the care of patients with breast cancer, their application requires trained healthcare professionals, enhanced technology, and accessible treatment. More importantly, breast cancer among premenopausal women should be included in the political and strategic agendas of developing countries to direct the necessary resources for prevention, detection, and control.

\section{REFERENCES}

1. Luengo-Fernandez R, Leal J, Gray A, et al. Economic burden of cancer across the European Union: a population-based cost analysis. Lancet Oncol. 2013;14:1165-74.

2. Galukande M, Kiguli-Malwadde E. Rethinking breast cancer screening strategies in resource-limited settings. Afr Health Sci. 2010;10:89-92.

3. DeSantis CE, Bray F, Ferlay J, et al. International variation in female breast cancer incidence and mortality rates. Cancer Epidemiol Biomarkers Prev. 2015;24:1495-506.

4. Ferlay J, Shin HR, Bray F, et al. Estimates of worldwide burden of cancer in 2008: GLOBOCAN 2008. Int J Cancer. 2010;127: 2893-917

5. Ghiasvand R, Adami HO, Harirchi I, et al. Higher incidence of premenopausal breast cancer in less developed countries; myth or truth? BMC Cancer. 2014;14:343.

6. Rodriguez-Cuevas S, Macias CG, Franceschi D, et al. Breast carcinoma presents a decade earlier in Mexican women than in women in the United States or European countries. Cancer. 2001;91:863-8.

7. Akarolo-Anthony SN, Ogundiran TO, Adebamowo CA. Emerging breast cancer epidemic: evidence from Africa. Breast Cancer Res. 2010;12(Suppl 4):S8.

8. Bowen RL, Duffy SW, Ryan DA, et al. Early onset of breast cancer in a group of British black women. Br J Cancer. 2008;98: 277-81.

9. Harirchi I, Ebrahimi M, Zamani N, et al. Breast cancer in Iran: a review of 903 case records. Public Health. 2000;114:143-5.

10. Jack RH, Davies EA, Moller H. Breast cancer and age in Black and White women in South East England. Int J Cancer. 2012;130: 1227-9. 
11. Villarreal-Garza C, Aguila C, Magallanes-Hoyos MC, et al. Breast cancer in young women in Latin America: an unmet, growing burden. Oncologist. 2013;18(Suppl):26-34.

12. Población entre 0 y 14 años de edad (\% del total). 2016. Available at http://datos.bancomundial.org/indicator/SP.POP.0014. TO.ZS?locations=NG.)

13. Kene TS, Odigie VI, Yusufu LM, et al. Pattern of presentation and survival of breast cancer in a teaching hospital in north Western Nigeria. Oman Med J. 2010;25:104-7.

14. Ghiasvand R, Maram ES, Tahmasebi S, et al. Risk factors for breast cancer among young women in southern Iran. Int J Cancer. 2011;129:1443-9.

15. Ravdin PM, Cronin KA, Howlader N, et al. The decrease in breastcancer incidence in 2003 in the United States. N Engl J Med. 2007;356:1670-4

16. Glass AG, Lacey JV, Carreon JD, et al. Breast cancer incidence, 1980-2006: combined roles of menopausal hormone therapy, screening mammography, and estrogen receptor status. J Natl Cancer Inst. 2007;99:1152-61.

17. Cragun D, Weidner A, Lewis C, et al. Racial disparities in BRCA testing and cancer risk management across a population-based sample of young breast cancer survivors. Cancer. 2017. (Epub ahead of print)

18. Torres-Mejia G, Royer R, Llacuachaqui M, et al. Recurrent BRCA1 and BRCA2 mutations in Mexican women with breast cancer. Cancer Epidemiol Biomarkers Prev. 2015;24:498-505

19. Sanchez-Zamorano LM, Flores-Luna L, Angeles-Llerenas A, et al. Healthy lifestyle on the risk of breast cancer. Cancer Epidemiol Biomarkers Prev. 2011;20:912-22.

20. Torres-Mejia G, Angeles-Llerenas A, Ortega-Olvera C, et al. Moderate-intensity physical activity ameliorates the breast cancer risk in diabetic women. Diabetes Care. 2012;35:2500-2.

21. Angeles-Llerenas A, Ortega-Olvera C, Perez-Rodriguez E, et al. Moderate physical activity and breast cancer risk: the effect of menopausal status. Cancer Causes Control. 2010;21:577-86.

22. Youlden DR, Cramb SM, Dunn NA, et al. The descriptive epidemiology of female breast cancer: an international comparison of screening, incidence, survival and mortality. Cancer Epidemiol. 2012;36:237-48

23. Sighoko D, Kamate B, Traore C, et al. Breast cancer in premenopausal women in West Africa: analysis of temporal trends and evaluation of risk factors associated with reproductive life. Breast. 2013;22:828-35.

24. Jung $S$, Spiegelman D, Baglietto $L$, et al. Fruit and vegetable intake and risk of breast cancer by hormone receptor status. J Natl Cancer Inst. 2013;105:219-36.

25. Linos E, Spanos D, Rosner BA, et al. Effects of reproductive and demographic changes on breast cancer incidence in China: a modeling analysis. J Natl Cancer Inst. 2008;100:1352-60.

26. Ziegler RG, Hoover RN, Pike MC, et al. Migration patterns and breast cancer risk in Asian-American women. J Natl Cancer Inst. 1993;85:1819-27.

27. Nelson NJ. Migrant studies aid the search for factors linked to breast cancer risk. J Natl Cancer Inst. 2006;98:436-8

28. Jatoi I, Anderson WF. Cancer screening. Curr Probl Surg. 2005;42:620-82

29. Porter P. "Westernizing" women's risks? Breast cancer in lowerincome countries. N Engl J Med. 2008;358:213-6.

30. Chavarri-Guerra Y, St Louis J, Liedke PE, et al. Access to care issues adversely affect breast cancer patients in Mexico: oncologists' perspective. BMC Cancer. 2014;14:658.

31. Boyd NF, Guo H, Martin LJ, et al. Mammographic density and the risk and detection of breast cancer. $N$ Engl J Med. 2007;356:227-36

32. Welch HG, Prorok PC, O'Malley AJ, et al. Breast-cancer tumor size, overdiagnosis, and mammography screening effectiveness. N Engl J Med. 2016;375:1438-47.

33. Thomas DB, Gao DL, Ray RM, et al. Randomized trial of breast self-examination in Shanghai: final results. J Natl Cancer Inst. 2002;94:1445-57

34. Semiglazov VF, Manikhas AG, Moiseenko VM, et al. [Results of a prospective randomized investigation [Russia (St.Petersburg)/ $\mathrm{WHO}$ ] to evaluate the significance of self-examination for the early detection of breast cancer]. Vopr Onkol. 2003;49:434-41.

35. Sankaranarayanan R, Ramadas K, Thara S, et al. Clinical breast examination: preliminary results from a cluster randomized controlled trial in India. J Natl Cancer Inst. 2011;103:1476-80.

36. Gadgil A, Sauvaget C, Roy N, et al. Cancer early detection program based on awareness and clinical breast examination: Interim results from an urban community in Mumbai, India. Breast. 2017:31:85-9.
37. Miller AB. Early detection of breast cancer in the emerging world. Zentralbl Gynakol. 2006;128:191-5

38. Gonzalez-Robledo LM, Gonzalez-Robledo MC, Nigenda G, et al. [Government actions for the early detection of breast cancer in Latin America. Future challenges]. Salud Publica Mex. 2010;52: 533-43.

39. Gutierrez-Rubio SA, Quintero-Ramos A, Duran-Cardenas A, et al. $1236 \mathrm{C} / \mathrm{T}$ and $3435 \mathrm{C} / \mathrm{T}$ polymorphisms of the $\mathrm{ABCB} 1$ gene in Mexican breast cancer patients. Genet Mol Res. 2015;14:1250-9.

40. Parkin DM, Fernandez LM. Use of statistics to assess the global burden of breast cancer. Breast J. 2006;12(Suppl 1):S70-80.

41. Zabicki K, Colbert JA, Dominguez FJ, et al. Breast cancer diagnosis in women $<$ or $=40$ versus 50 to 60 years: increasing size and stage disparity compared with older women over time. Ann Surg Oncol. 2006;13:1072-7

42. Ahn SH, Son BH, Kim SW, et al. Poor outcome of hormone receptor-positive breast cancer at very young age is due to tamoxifen resistance: nationwide survival data in Korea--a report from the Korean Breast Cancer Society. J Clin Oncol. 2007;25:2360-8

43. Yankaskas BC. Epidemiology of breast cancer in young women Breast Dis. 2005;23:3-8.

44. Villarreal-Garza C, Mohar A, Bargallo-Rocha JE, et al. Molecular subtypes and prognosis in young Mexican women with breast cancer. Clin Breast Cancer. 2016. (Epub ahead of print).

45. Rouhollahi MR, Mohagheghi MA, Mohammadrezai N, et al. Situation analysis of the National Comprehensive Cancer Control Program (2013) in the I. R. of Iran; assessment and recommendations based on the IAEA imPACT mission. Arch Iran Med. 2014;17:222-31

46. Love RR, Duc NB, Baumann LC, et al. Duration of signs and survival in premenopausal women with breast cancer. Breast Cancer Res Treat. 2004;86:117-24

47. Malik AM, Pathan R, Shaikh NA, et al. Pattern of presentation and management of ca breast in developing countries. There is a lot to do. J Pak Med Assoc. 2010;60:718-21.

48. Pakseresht S, Ingle GK, Garg S, et al. Stage at diagnosis and delay in seeking medical care among women with breast cancer, Delhi, India. Iran Red Crescent Med J. 2014;16:e14490.

49. Unger-Saldana K, Infante-Castaneda CB. Breast cancer delay: a grounded model of help-seeking behaviour. Soc Sci Med. 2011:72:1096-104

50. NORMA Oficial Mexicana NOM-041-SSA2-2011, Para la prevención, diagnóstico, tratamiento, control y vigilancia epidemiológica del cáncer de mama. 2011. Available at: http://www. dof gob $\mathrm{mx} /$ nota detalle php? codigo $=5194157 \& \mathrm{fec}$ ha=09/06/2011. (Accessed March 16 2017).

51. Freitas AG, Weller M. Patient delays and system delays in breast cancer treatment in developed and developing countries. Cien Saude Colet. 2015;20:3177-89.

52. Angeles-Llerenas A, Torres-Mejia G, Lazcano-Ponce E, et al. Effect of care-delivery delay on the survival of Mexican women with breast cancer. Salud Publica Mex. 2016;58:237-50.

53. Unger-Saldana K, Miranda A, Zarco-Espinosa G, et al. Health system delay and its effect on clinical stage of breast cancer: Multicenter study. Cancer. 2015;121:2198-206.

54. Alves Soares Ferreira N, Melo Figueiredo de Carvalho S, Engracia Valenti V, et al. Treatment delays among women with breast cancer in a low socio-economic status region in Brazil. BMC Womens Health. 2017;17:13.

55. Jatoi I, Benson JR. Management of women with a hereditary predisposition for breast cancer. Future Oncol. 2016;12:2277-88.

56. Waks AG, Partridge $A H$. fertility preservation in patients with breast cancer: necessity, methods, and safety. J Natl Compr Canc Netw. 2016;14:355-63

57. de la Noval BD. Potential implications on female fertility and reproductive lifespan in BRCA germline mutation women. Arch Gynecol Obstet. 2016;294:1099-103.

58. Villarreal-Garza C, Martinez-Cannon BA, Platas A, et al. Fertility concerns among breast cancer patients in Mexico. Breast. 2017:33:71-5.

59. Blinder V, Patil S, Eberle C, et al. Early predictors of not returning to work in low-income breast cancer survivors: a 5-year longitudinal study. Breast Cancer Res Treat. 2013;140:407-16.

60. Bird PA, Hill AG, Houssami N. Poor hormone receptor expression in East African breast cancer: evidence of a biologically different disease? Ann Surg Oncol. 2008;15:1983-8.

61. Huo D, Ikpatt F, Khramtsov A, et al. Population differences in breast cancer: survey in indigenous African women reveals overrepresentation of triple-negative breast cancer. J Clin Oncol. 2009;27:4515-21. 
62. Turkoz FP, Solak M, Petekkaya I, et al. Association between common risk factors and molecular subtypes in breast cancer patients. Breast. 2013;22:344-50

63. Trinkaus ME, Sayed S, Gakinya SM, et al. Triple negative and basal-like breast cancer in East Africa. Breast J. 2011;17:438-40.

64. Gordon NH. Socioeconomic factors and breast cancer in black and white Americans. Cancer Metastasis Rev. 2003.22:55-65.

65. Anderson WF, Chu KC, Chang S, et al. Comparison of age-specific incidence rate patterns for different histopathologic types of breast carcinoma. Cancer Epidemiol Biomarkers Prev. 2004; 13:1128-35.

66. Hutchinson L. Screening: BRCA testing in women younger than 50 with triple-negative breast cancer is cost effective. Nat Rev Clin Oncol. 2010;7:611

67. Villarreal-Garza C, Weitzel JN, Llacuachaqui M, et al. The prevalence of BRCA1 and BRCA2 mutations among young Mexican women with triple-negative breast cancer. Breast Cancer Res Treat. 2015;150:389-94.

68. Partridge $\mathrm{AH}$, Hughes ME, Ottesen RA, et al. The effect of age on delay in diagnosis and stage of breast cancer. Oncologist. 2012;17:775-82

69. El Saghir NS, Adebamowo CA, Anderson BO, et al. Breast cancer management in low resource countries (LRCs): consensus statement from the Breast Health Global Initiative. Breast. 2011;20(Suppl 2):S3-11.

70. Harford J, Azavedo E, Fischietto M, et al. Guideline implementation for breast healthcare in low- and middle-income countries: breast healthcare program resource allocation. Cancer. 2008;113:2282-96.

71. Allemani C, Weir HK, Carreira H, et al. Global surveillance of cancer survival 1995-2009: analysis of individual data for $25,676,887$ patients from 279 population-based registries in 67 countries (CONCORD-2). Lancet. 2015;385:977-1010.

72. Health expenditure per capita (current US\$). 2014. Available at: http://data.worldbank.org/indicator/SH.XPD.PCAP/countries/XM?display=graph. (Accessed March 16, 2017).

73. Jemal A, Tiwari RC, Murray T, et al. Cancer statistics, 2004. CA Cancer J Clin. 2004;54:8-29.

74. Pichon-Riviere A, Garay OU, Augustovski F, et al. Implications of global pricing policies on access to innovative drugs: the case of trastuzumab in seven Latin American Countries. Int ] Technol Assess Health Care. 2015;31:2-11.

75. Ventura-Alfaro CE, Torres-Mejia G, Avila-Burgos Ldel S. Hospitalization and mortality in Mexico due to breast cancer since its inclusion in the catastrophic expenditures scheme. Salud Publica Mex. 2016;58:187-96.

76. Knaul FM, Gonzalez-Pier E, Gomez-Dantes $\mathrm{O}$, et al. The quest for universal health coverage: achieving social protection for all in Mexico. Lancet. 2012;380:1259-79.

77. Vargas-Rivas JE, Montes-Casas MM, Cancela-Diez B, et al. Study of compliance with prescription information sheet of trastuzumab prescriptions in a tertiary level hospital. Farm Hosp. 2012;36:135-40.

78. Schnipper LE, Smith TJ, Raghavan D, et al. American Society of Clinical Oncology identifies five key opportunities to improve care and reduce costs: the top five list for oncology. J Clin Oncol. 2012;30:1715-24

79. Capri S, Russo A. Cost of breast cancer based on real-world data: a cancer registry study in Italy. BMC Health Serv Res. 2017;17:84.

80. Bazargani YT, de Boer A, Schellens JH, et al. Essential medicines for breast cancer in low and middle income countries. BMC Cancer. 2015;15:591.

81. Kotsopoulos J, Huzarski T, Gronwald J, et al. Bilateral oophorectomy and breast cancer risk in BRCA1 and BRCA2 mutation carriers. J Natl Cancer Inst. 2016;109.

82. Anderson BO, Yip CH, Ramsey SD, et al. Breast cancer in limitedresource countries: health care systems and public policy. Breast J. 2006:12(Suppl 1):S54-69.

83. McCutcheon S, Cardoso F. Challenges in optimizing care in advanced breast cancer patients: Results of an international survey linked to the $A B C 1$ consensus conference. Breast. 2015;24:623-9.

84. Goldhirsch A, Winer EP, Coates AS, et al. Personalizing the treatment of women with early breast cancer: highlights of the St Gallen International Expert Consensus on the Primary Therapy of Early Breast Cancer 2013. Ann Oncol. 2013;24:2206-23.

85. Kantelhardt EJ, Cubasch $\mathrm{H}$, Hanson $\mathrm{C}$. Taking on breast cancer in East Africa: global challenges in breast cancer. Curr Opin Obstet Gynecol. 2015;27:108-14. 